\title{
TYPING OF PROTEUS STRAINS BY PROTICINE PRODUCTION AND SENSITIVITY
}

\author{
B. W. SENIOR \\ Department of Bacteriology, University of Dundee, Dundee DDI $4 H N$
}

THE incidence of severe proteus infections appears to be increasing (Finland, 1960; Lewis and Fekety, 1969). Proteus strains are frequently implicated in infections of wounds, burns and the urinary tract. Bloodstream infection, which may be accompanied by bacteriaemic shock, has a high mortality (Lewis and Fekety, 1969). Proteus meningo-encephalitis in neonates, often accompanied by umbilical sepsis, is usually fatal (Shortland-Webb, 1968; Burke et al., 1971). Because infection may be either exogenous or endogenous, the extent of proteus cross-infection will continue to be difficult to assess until examined with an accurate typing scheme.

Proteus strains have been typed on the basis of their antigenic structure (Belyavin, Miles and Miles, 1951; Krikler, 1953), biochemical characters and phage sensitivity (Kippax, 1957; Huang, 1966; France and Markham, 1968), Dienes type (Krikler, 1953; Story, 1954; de Louvois, 1969; Skirrow, 1969); resistotype (Kashbur, George and Ayliffe, 1974) and bacteriocine production (Cradock-Watson, 1965), but none of these methods has gained general preference for use in epidemiological studies.

This paper reports a further bacteriocine typing method which led to the discovery of several new types and subtypes of bacteriocine (proticine) and the development of a new, highly discriminating method of typing Proteus by the combined observation of proticine production and proticine sensitivity.

\section{MATERIALS AND METHODS}

Strains. Two hundred and fifty strains of Proteus were isolated at random from samples of urine, faeces and pus received for routine bacteriological examination. Presumptive proteus strains were plated out on MacConkey's agar. One colony from each sample was isolated and maintained on a nutrient-agar slope in a screw-capped bottle at $4^{\circ} \mathrm{C}$ in the dark. Strains that failed to ferment lactose yet hydrolysed urea were identified as Proteus and were later assigned to different species by their reactions in maltose and mannitol peptone water and their formation of indole in Tryptone Water (Oxoid).

Subcultures of the standard set of 24 proticine-indicator strains and the 10 different proticine-producing type strains isolated by Dr J. E. Cradock-Watson were kindly donated by Mr T. L. Pitt of the Cross-Infection Reference Laboratory, Colindale, London.

Typing of strains for proticine production and sensitivity. Five wells of a sterile perspex virus-haemagglutination tray were filled with tryptone-water cultures of the strains under test as producer strains. A multiple inoculator, consisting of a typist's rubber holding five wire loops, was charged from the culture reservoirs and streaked across the surface of MacConkey Agar (Oxoid CM7) in plastic disposable petri dishes. After incubation at $37^{\circ} \mathrm{C}$ for $18-24 \mathrm{~h}$,

Received 2 Apr. 1976; accepted 6 May 1976.

J. MED. MICROBIOL.-VOL. 10 (1977) 
TABLE I

Cradock-Watson (CW) scheme of Proticine typing of proteus strains by their spectrum of inhibitory activity against 24 standard indicator strains, and the types of 250 Dundee isolates determined by its use

\begin{tabular}{|c|c|c|c|c|c|c|c|c|c|c|c|c|c|c|c|c|c|c|c|c|c|c|c|c|c|c|}
\hline \multirow{2}{*}{$\begin{array}{c}\text { Proticine type } \\
\text { of } \\
\text { producer } \\
\text { strain }\end{array}$} & \multirow{2}{*}{$\begin{array}{c}\text { CW } \\
\text { Standard } \\
\text { producer } \\
\text { strain } \\
\text { no. }\end{array}$} & \multicolumn{24}{|c|}{ Inhibition of $\mathrm{CW}$ indicator strain no. } & \multirow{2}{*}{$\begin{array}{l}\text { Number of } \\
\text { Dundee } \\
\text { isolates } \\
\text { allocated } \\
\text { to the } \\
\text { indicated } \\
\text { type }\end{array}$} \\
\hline & & 175 & 664 & 794 & 816 & 337 & 784 & 537 & 823 & 1 & 11 & 52 & 712 & 106 & 122 & 261 & 276 & 4 & 380 & 384 & 792 & 335 & 565 & 630 & 818 & \\
\hline 1 & 535/A & + & + & + & + & - & + & - & - & - & - & - & - & + & - & - & - & - & - & - & - & - & - & - & - & 36 \\
\hline 3 & 977 & - & - & - & - & - & - & - & - & - & + & + & + & - & - & - & - & - & - & - & - & - & - & - & - & 20 \\
\hline 4 & 404/A & - & - & - & - & - & - & - & - & - & - & - & - & - & - & - & - & + & + & + & + & - & - & - & - & 13 \\
\hline 5 & 867 & - & - & - & - & - & - & - & - & - & - & + & - & \pm & + & + & + & - & - & - & - & - & - & - & - & 20 \\
\hline 6 & 237 & - & - & - & - & - & - & - & - & + & - & - & - & - & - & - & - & - & - & - & - & - & - & - & - & 6 \\
\hline 7 & 677 & - & - & - & - & - & - & - & - & - & - & - & - & - & - & - & - & + & - & - & - & + & + & + & + & 6 \\
\hline 8 & 927 & - & - & - & - & + & + & + & - & - & - & - & - & - & - & - & - & - & - & - & - & - & - & - & - & 8 \\
\hline 9 & 516 & - & - & - & - & - & - & - & + & - & - & - & - & - & - & - & - & - & - & - & - & - & - & - & - & 5 \\
\hline 10 & 349 & - & - & - & - & - & - & - & - & - & - & - & - & - & - & - & - & - & - & + & + & + & + & - & - & 6 \\
\hline Non-producers & $\cdots$ & - & - & - & - & - & - & - & - & - & - & - & - & - & - & - & - & - & - & - & - & - & - & - & - & 62 \\
\hline
\end{tabular}

$+=$ Inhibition of indicator; $\pm=$ partial or variable inhibition; $-=$ no inhibition of indicator

* Only five of the "atypical " producer strains inhibited the indicators marked $(+)$, and each of these producer strains inhibited only one of these indicators. 
the growth was removed to one side of the plate by means of a microscope slide covered in Sellotape to minimise scratching of the agar surface. The plates were sterilised by inverting them and resting them for $10 \mathrm{~min}$. on the rim of the base of a 9-cm-diameter glass petri dish holding chloroform. The plates were then removed and left inverted and open for about $30 \mathrm{~min}$. at room temperature to allow toxic vapours to disperse.

By use of the multiple inoculator, 3-h tryptone-water cultures of indicator strains, or strains under test for proticine sensitivity, were subsequently streaked across these plates at right angles to the lines of growth of the producer strains. After overnight incubation at $37^{\circ} \mathrm{C}$, the plates were examined and any inhibition of growth was recorded. In cases of doubtful sensitivity, plates were examined as soon as growth of the indicator strain was visible.

\section{RESULTS}

Biochemical tests showed that 221 strains (56 from faeces, 135 from urine and 30 from pus) were Proteus mirabilis, 26 strains (17 from faeces, six from urine and three from pus) were $P$. morganii and only three strains (two from faeces and one from pus) were $P$. vulgaris. No strains giving biochemical reactions typical of $P$. rettgeri were isolated.

The 250 strains were categorised as either proticine producers or indicators by testing all 250 against each other-a total of 62500 tests.

\section{Proticine-producing strains}

Approximately $75 \%(188)$ of the strains were found spontaneously to produce proticine active against one or more of the 250 strains used as indicators while 62 strains failed to produce proticine under these conditions. The proticineproducing strains were tested against the 24 standard Cradock-Watson (CW) indicator strains with the results shown in table I.

Of the 188 proticinogenic strains, 138 produced proticines indistinguishable in their spectrum of activity on the standard CW indicators from those produced by the standard $\mathrm{CW}$ producer strains. The remaining 50 had either no activity on any of the CW indicators or had spectra of activity different from that of any of the standard $\mathrm{CW}$ producer strains. These 50 strains were at this stage designated " atypical" producers.

Eighty-four per cent of the P. mirabilis strains were proticinogenic. However, none of the three strains of $P$. vulgaris and only three of the 26 strains of $P$. morganii produced proticines; of the latter three, one belonged to CWtype 5 and the other two were "atypical". The source of the proteus strain appeared to have little or no influence on proticinogeny or proticine typeall 10 different $\mathrm{CW}$ proticine types being found in urinary isolates $(64 \%$ were proticinogenic) and most of them also in faeces and pus (39\% and 50\% respectively were proticinogenic).

Strains that produced proticines of type 1 were by far the most frequent $(14 \%)$ of the producer strains isolated, followed by strains that produced proticines of types $2,3,4$ and $5(5-8 \%)$. The strains producing other types of proticines were seen less frequently $(2 \%)$.

All the 36 type-1 producers were indistinguishable in their action against 
the Cradock-Watson type- 1 indicators and a further 44 newly isolated indicators. However, their reactions against the 10 indicators listed in table II allowed

TABLE II

Action spectra of six subtypes among 36 Cradock-Watson (CW) type-1 producer strains in tests with $C W$ strain 818 and nine new indicator strains

\begin{tabular}{|c|c|c|c|c|c|c|c|c|c|c|c|}
\hline \multirow{2}{*}{$\begin{array}{l}\text { Producer } \\
\text { subtype }\end{array}$} & \multicolumn{10}{|c|}{ Inhibition of indicator strain } & \multirow{2}{*}{$\begin{array}{l}\text { No. of strains } \\
\text { in Dundee series }\end{array}$} \\
\hline & 818 & E2 & G9 & H4 & H8 & 19 & J3 & L1 & P8 & $\mathrm{S} 2$ & \\
\hline $1 \mathrm{a}$ & - & - & + & - & - & + & - & - & + & + & 18 \\
\hline $1 \mathrm{~b}$ & - & - & + & - & - & + & - & + & + & + & 6 \\
\hline $1 \mathrm{c}$ & - & - & + & - & - & + & - & - & - & + & 9 \\
\hline $1 \mathrm{~d}$ & - & + & + & + & - & + & + & - & + & + & 1 \\
\hline $1 \mathrm{e}$ & + & - & + & - & + & + & - & - & + & + & 1 \\
\hline If & - & - & - & - & - & - & - & - & - & + & 1 \\
\hline
\end{tabular}

$+=$ Inhibition of indicator; $-=$ no inhibition of indicator.

the subdivision of the type- 1 producers into six subtypes. The standard $\mathrm{CW}$ type-1 producer strain (535/A) belongs to subtype 1a.

Similarly, the 18 type-2 producing strains, indistinguishable in their action on CW type-2 indicators and a further three newly isolated indicators, could be subdivided by their action on the three indicators listed in table III. The

TABLE III

Action spectra of subtypes among Cradock-Watson (CW) type-2 and type-3 producing strains in tests with $C W$ strains $1,11,52$ and 712 and eleven new indicator strains

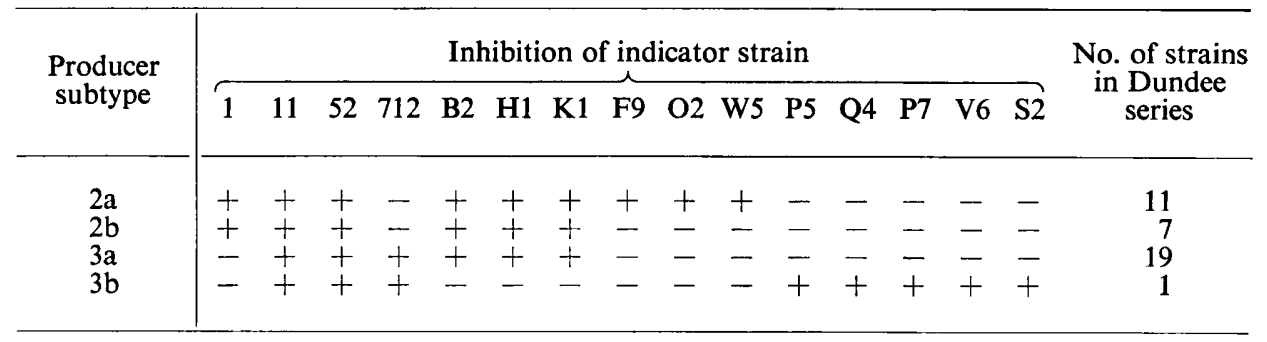

$+=$ Inhibition of indicator; $-=$ no inhibition of indicator.

standard CW type-2 producer strain (362) is of subtype 2a. Furthermore, the 20 type-3 producing strains, indistinguishable in their action on CW type-3 indicators, could be subdivided into two subgroups according to their action on a further eight indicators (table III). The standard CW type-3 producing strain (977) is of subtype 3a.

Of the 50 strains producing "atypical" proticines, only five produced proticines acting on one or more of the 24 standard CW indicators (table I) and the remaining 45 proticinogenic strains had no action on these indicators and therefore were of producer types other than CW 1-10. Three new types 
TABLE IV

Proposed new scheme of proticine " producer/sensitivity" typing by determination of both the producer type (P type) and sensitivity type (S type) of the unknown strain

\begin{tabular}{|c|c|c|c|c|c|c|c|c|c|c|c|c|c|c|}
\hline \multirow{3}{*}{$\begin{array}{l}\text { P type of strain (and } \\
\text { designation of standard } \\
\text { P-type strain) }\end{array}$} & \multicolumn{14}{|c|}{$\begin{array}{l}\text { Sensitivity of indicator (S-type) strains to P-type strain } \\
\text { (and designation of standard S-type strains) }\end{array}$} \\
\hline & $\stackrel{\text { J }}{\mathrm{N}}$ & $\stackrel{\overparen{n}}{=}$ & 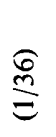 & $\frac{\overparen{\Xi}}{\Xi}$ & $\underset{\infty}{\infty}$ & $\widehat{\overparen{\mathcal{d}}}$ & $\stackrel{\infty}{2}$ & ఠ్ల్ర & 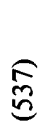 & 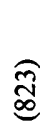 & $\stackrel{\text { 尹 }}{\Xi}$ & $\stackrel{\widehat{\Xi}}{\varrho}$ & $\stackrel{n}{\Xi}$ & $\stackrel{\infty}{\sum}$ \\
\hline & S0 & S1 & $\mathbf{S 2}$ & S3 & S4 & S5 & S6 & S7 & S8 & S9 & S10 & S11 & S12 & S13 \\
\hline P0 (Z4) & - & - & - & - & - & - & - & - & - & - & - & - & - & - \\
\hline P1 (535/A) & - & + & - & - & - & - & - & - & - & - & - & - & - & - \\
\hline P2 (362) & - & - & + & - & - & - & - & - & - & - & - & - & - & - \\
\hline P3 (977) & - & - & - & + & - & - & - & - & - & - & - & - & - & - \\
\hline P4 (404/A) & - & - & - & - & + & - & - & - & - & - & - & - & - & - \\
\hline P5 (867) & 一 & - & - & - & - & + & - & - & - & - & - & - & - & - \\
\hline P6 (237) & $\rightarrow$ & - & - & - & - & - & + & - & - & - & - & - & - & - \\
\hline P7 (677) & - & - & - & - & - & - & - & + & - & - & - & - & - & - \\
\hline P8 (927) & - & - & - & - & - & - & - & - & + & - & - & - & - & - \\
\hline P9 (516) & - & - & - & - & - & - & - & - & - & + & - & - & - & - \\
\hline P10 (349) & - & - & - & - & - & - & - & - & - & - & + & - & - & - \\
\hline P11 (M6) & - & - & - & - & - & - & - & - & - & - & - & + & - & - \\
\hline P12 (U6) & - & - & - & - & - & - & - & - & - & - & - & - & + & - \\
\hline P13 (N8) & - & - & - & - & - & - & - & - & - & - & - & - & - & + \\
\hline
\end{tabular}

$+=$ Inhibition of indicator strain $;-=$ no inhibition of indicator strain.

The production by an unknown strain of a proticine active against one of the standard indicator strains gives the $P$ type of the unknown strain. The sensitivity of the unknown strain to one or more of the proticines produced by the standard producer strains gives its $\mathbf{S}$ type.

(types 11, 12 and 13) of proticine producer strains were defined and characterised among these 45 strains.

Seven type-11 producing strains were isolated from faeces and urine and acted on $10 P$. mirabilis strains, of which five were specifically sensitive to type 11 proticine.

One type-12 producing strains was isolated from urine. It acted on 20 indicators, none of which was specific to type-12 proticine. Although only one of the type- 12 indicators was sensitive to type-11 proticine, the types were clearly distinct, for two of the type-12 indicators were type-11 producers.

Two type-13 producing strains were isolated from pus and urine. Both were sensitive to type-12 proticine and acted on 22 indicators of which one was specific for type 13 and one was a type-12 producer.

Strains representing each of these three newly defined proticine producer types have been included with $10 \mathrm{CW}$ strains in the list of standard producer strains used in the new typing scheme (table IV).

\section{Proticine-sensitive strains}

One hundred and thirty-three proteus strains were sensitive to one or more of the standard CW proticine-producing strains. Among these were 127 
TABLE V

Distribution of the different patterns of proticine sensitivity ( $S$ type) among the proticineproducing and non-producing strains of the Dundee series. Forty $S$ types and $90 \mathrm{P} / \mathrm{S}$ types were recognised among 250 proteus strains

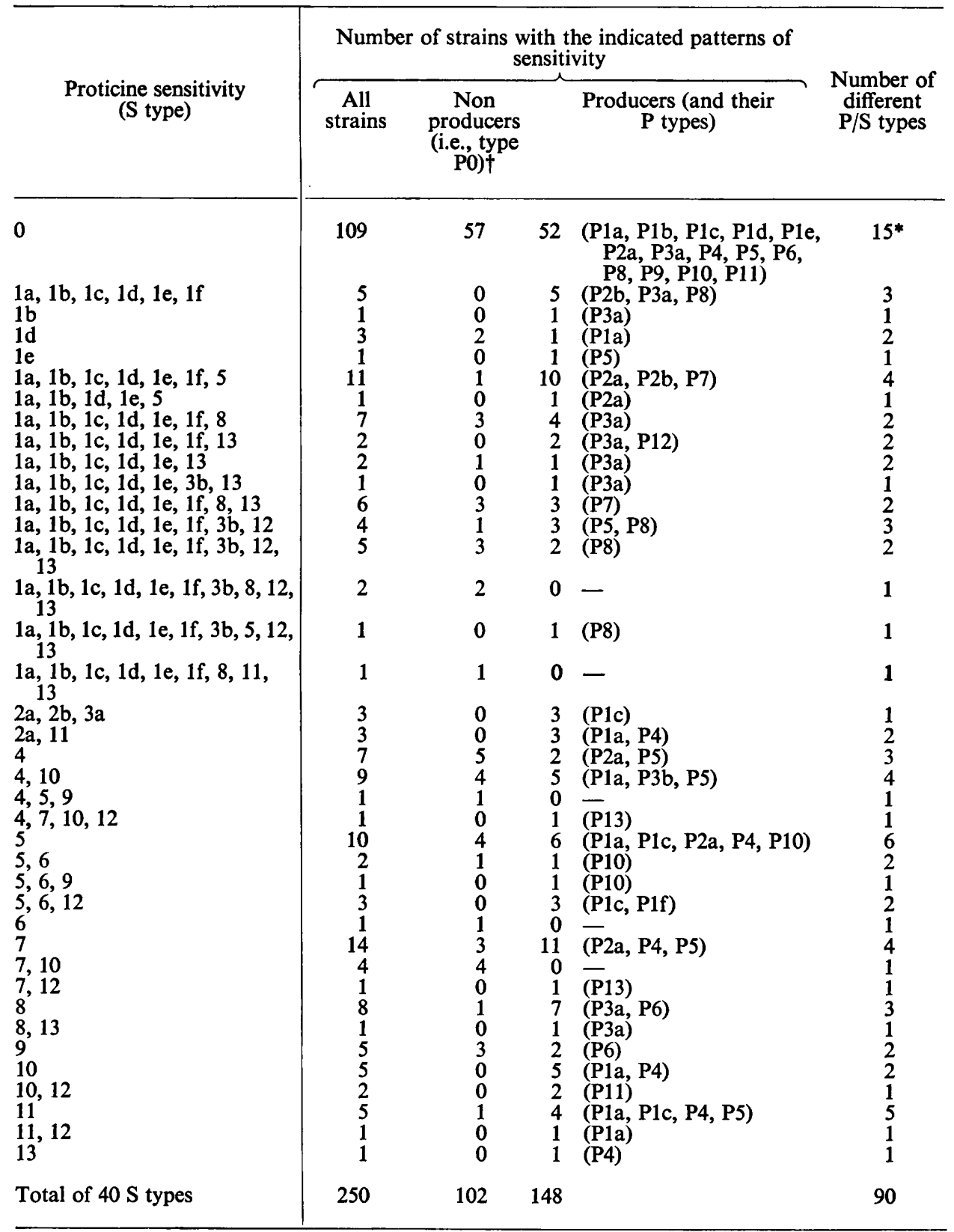

* Includes P0/S0 types.

$\dagger$ Strains not producing proticines of types 1-13. 
strains of $P$. mirabilis (58\% of the species), four strains of $P$. morganii and two strains of $P$. vulgaris. An additional 38 strains were sensitive to " atypical" proticines. Only six of the $26 P$. morganii strains were sensitive to proticines; two to a type-4 proticine, two to a type- 5 proticine and two to "atypical" proticines. Two of the three $P$. vulgaris strains were sensitive to proticines, one to a type-4 and the other to a type-7 proticine.

Strains sensitive to all types of proticine were found among isolates from urine and faeces. Those from pus were sensitive to 11 proticines. Table $\mathrm{V}$ shows the frequency of occurrence of sensitivity to the different types of proticine among the 250 proteus strains examined.

Proticine-sensitive strains were often found to be sensitive to more than one type of proticine. Indeed, one strain was sensitive to five different proticines. Analysis of the proticine sensitivities of the strains shown in table $\mathrm{V}$ revealed that among strains sensitive to a given proticine, any additional heterologous proticine sensitivity was usually confined to a small number of proticines and not randomly distributed throughout the different proticine types. Thus heterologous sensitivity among strains sensitive to proticine of type 1 was confined to proticines of types $5,8,12$ and 13. Similarly, heterologous sensitivity among strains sensitive to type-10 proticine was usually confined to proticines of type 4 or 7 . Among the 250 strains examined there were 40 different patterns of proticine sensitivity.

No producing strain was sensitive to its own proticine, although it may have possessed the receptors for that proticine. One strain that produced a proticine of type 1a was sensitive to a proticine of type 1d, which supports the conclusion that the subtypes of proticine 1 are different. Proticineproducing strains were frequently observed to be sensitive to several different proticines and these sensitivity characteristics permitted further discrimination among hitherto indistinguishable strains. There appeared to be no correlation between the type of proticine formed and the proticine sensitivity, so that observation of both properties gave maximum discrimination.

Indicator strains that had a single, unique proticine sensitivity were selected from the 250 proteus strains and the $\mathrm{CW}$ indicator strains. These standard indicator strains and their proticine sensitivities are presented in table IV.

In all, 27 strains, comprising seven of 221 strains of $P$. mirabilis, 19 of 26 strains of $P$. morganii and one of three strains of $P$. vulgaris were neither proticine producers nor sensitive to proticine. One of these strains, no. Z4, has been included in the new typing scheme presented in table IV.

\section{The proticine producer/sensitivity typing of Proteus strains}

To simplify the typing of strains for proticine production and sensitivity, it is suggested that indicators should be used which have a stable and, wherever possible, a single specific proticine sensitivity. In the proposed new typing scheme, the $\mathrm{CW}$ indicators for proticines 2,6 and 10 are considered to be unsuitable because of their sensitivity to more than one proticine; these indicators have been substituted by others having a single, specific proticine 
sensitivity. The indicator for proticine 2 was isolated from the parent strains CW1 (sensitive to proticines 2 and 6) as a mutant resistant to proticine 6 and sensitive to proticine 2 (indicator strain 1/36). Indicator strain A4/115 was isolated from the parent strain A4 (sensitive to proticines 11 and 12) as a mutant colony resistant to proticine 11 .

It is suggested that strains to be typed should be tested for proticine production against the indicator strains listed and also for proticine sensitivity to the producer strains listed. Strains producing proticines of type 1, 2 or 3 can be subtyped where necessary by their action against the indicators listed in tables II and III.

The proticine producer/sensitivity $(\mathrm{P} / \mathrm{S})$ type of a strain is recorded as, for example, $\mathrm{P} 3 \mathrm{a} / \mathrm{S} 4,10$; this indicates that it produces proticine of type 3 subtype a and is sensitive to proticines of types 4 and 10. A strain of P/S-type $\mathrm{P} 3 \mathrm{a} / \mathrm{SO}$ produces proticine of type 3 subtype a and is resistant to all proticines, and a strain of $\mathrm{P} / \mathrm{S}$-type $\mathrm{PO} / \mathrm{S} 4,10$ fails to produce proticine and is sensitive to proticines of types 4 and 10 .

\section{DisCUSSION}

A simple and reliable new scheme for the bacteriocine (proticine) typing of Proteus has been developed that is more discriminating than previous typing schemes of this kind. Strains are typed on MacConkey's agar, first for the production of a proticine active against one of a standard set of indicators that have a single and unique proticine sensitivity and then for sensitivity to one or more of the proticines produced by a standard set of proticine-producing strains.

Cradock-Watson (1965, and later personal communication) showed that Proteus could be subdivided into at least 10 different types on the basis of the action spectra of their proticines against 24 indicator strains. Other workers have typed different collections of proteus strains against these same indicators and found proticinogenic strains to occur with a frequency of $6 \%$ (Tracy and Thompson, 1972), 74\% (Adler et al., 1971) and 85\% (George, 1974). However, the Cradock-Watson scheme is unsatisfactory in certain respects. It is insufficiently discriminatory; many of the indicators are sensitive to more than one proticine type and some, being of the same Dienes types, are apparently duplicate strains; moreover, the Cradock-Watson indicators are resistant to many hitherto undetected proticines.

In this study, 250 proteus strains were tested among themselves in every combination as producers and indicators to determine their proticine production and sensitivity. In addition, the strains were tested for production of proticines active against the Cradock-Watson indicators. Forty-five strains were shown to produce proticines having no action on the Cradock-Watson indicators. Furthermore, the number of different patterns of inhibition was increased from 10 , as shown by the Cradock-Watson indicators, to 20 , as shown with my indicators.

Although proticine production may be better on other media than the one I employed (George, 1974) and "induction" techniques might have identified 
even more proticinogenic strains, the typing of strains for proticine production on MacConkey's agar, on which swarming is absent, has proved to be technically simple, reliable and readily applicable to several strains together. My initial studies have shown that with some of the producing strains, proticines can be detected within $6 \mathrm{~h}$ at $37^{\circ} \mathrm{C}$. However, production by other strains requires incubation for $18 \mathrm{~h}$. Because no producing strain was found which required a longer incubation period before proticine could be detected, $18 \mathrm{~h}$ was the routine period allowed for proticine production.

The source of the proteus strain appeared to have influence neither on proticinogeny nor on type, but the species was important. P. morganii strains were rarely proticinogenic $(11 \%)$, whereas $84 \%$ of the $P$. mirabilis strains were proticine producers. The frequency of the different proticinogenic types among the 250 Dundee strains was very similar to that found by CradockWatson (personal communication) for his strains from different English public health laboratories. In both instances, proticine type-1 producing strains were by far the most frequently isolated, and strains producing proticine of types 6 and 9 were quite rare. In contrast, Adler et al. (1971) found strains producing proticines of type 6 and type 9 to be among the most frequently isolated proteus strains in Boston, USA.

Occasionally, inhibition of growth of indicator strains was shown to be the result of phage activity. Since the present typing scheme is based on proticine action, phage action was not recorded. None of the type-producer strains was found to be lysogenic. Al-Jumaili (1975a and $b$ ) has recently typed $P$. mirabilis and $P$. vulgaris by their sensitivity to " proticines". He found 48 different patterns of sensitivity and claimed that all the 1805 strains tested were typable by his method. However, the validity of this typing scheme is questionable, because it is possible that the sterile supernates of mitomycin-C induced liquid cultures of proteus strains that he used as "proticine" preparations were contaminated in certain instances with bacteriophages. This might explain why no "proticine" resistant strains were found among 1805 tested against 12 " proticines", whereas in my typing scheme, in which strains were tested against a larger number of spontaneously produced proticines, and in which phage action was observed but was not scored, a significant proportion of strains appeared to be proticine resistant.

The sensitivity of a strain to a proticine appears to be a somewhat less stable character than the property of proticine production. Small resistant mutant colonies appear from time to time in areas of inhibited growth. Moreover, old and very dense cultures of some indicator strains are relatively proticine resistant. Whether this is the outcome of the denser cultures per se or the products of metabolism in the culture medium, is unclear. To minimise these types of variation, indicator strains and those under test as indicators were always taken from young cultures.

As with proticinogenicity, the origin of the Proteus strain appeared to have no influence on sensitivity to proticine, whereas the species of Proteus was a major determinant. Seventy-four per cent of $P$. mirabilis strains were sensitive to one or more proticines whereas only $23 \%$ of $P$. morganii strains were 
sensitive. From sensitivity alone, the 250 proteus strains could be divided into 40 different combinations of sensitivity.

In the proposed new "production/sensitivity" typing scheme, strains are typed both for proticine production and for proticine sensitivity. By selecting indicator strains each having a single, distinct sensitivity to one of the 14 newly defined proticine production types, the number of indicator strains has been reduced from 24 to 14 . Thus the effort required to type strains by the new method is only marginally greater than that required by the Cradock-Watson "production" typing scheme, but whereas the Cradock-Watson scheme differentiated my 250 strains into 10 P-types, the new typing scheme differentiates them into $90 \mathrm{P} / \mathrm{S}$-types and so is very much more discriminating.

\section{SUMMARY}

A simple, reliable and highly discriminating scheme for the bacteriocine typing of Proteus has been developed. Strains are typed on MacConkey's agar according to their ability to produce a proticine active against one of 14 indicator strains having a single and specific proticine sensitivity and also according to their sensitivity to the different proticines of 13 proticine-producing strains. This new scheme of combined production and sensitivity typing was formulated after 250 strains of Proteus from clinical material had been examined for the production of proticines active against the 24 indicator strains of Cradock-Watson's proticine typing scheme and for proticine activity and sensitivity towards each other. Three new types of proticinogenic strains were discovered and defined. Strains producing proticines of types 1, 2 and 3 were isolated frequently. These common proticines could be subtyped by their different actions on newly characterised indicator strains.

By means of this production/sensitivity $(\mathrm{P} / \mathrm{S})$ typing scheme, 250 Proteus strains were differentiated into 90 distinct types, whereas typing by sensitivity alone distinguished only 40 types and typing by production alone distinguished only 20 types (including subtypes).

\section{REFERENCES}

Adler, J. L., Burke, J. P., Martin, D. F. And Finland, M. 1971. Proteus infection in a general hospital. 1. Biochemical characteristics and antibiotic susceptibility of the organisms with special reference to proticine typing and Dienes phenomena. Annls int. Med., 75, 517.

Al-Jumaili, I. J., 1975a. Bacteriocine typing of Proteus. J. clin. Path., 28, 784.

Al-Jumaili, I. J., 1975b. An evaluation of two methods of bacteriocine typing of organisms of the genus Proteus. J. clin. Path., 28, 788.

Belyavin, G., Miles, E. M. And Miles, A. A. 1951. The serology of fifty strains of Proteus vulgaris. J. gen. Microbiol., 5, 178.

Burke, J. P., Ingall, D., Klein, J. O., Gezon, H. M. And Finland, M. 1971. Proteus mirabilis infections in a hospital nursery traced to a human carrier. New Engl. J. Med., 284, 115.

Cradock-Watson, J. E. 1965. The production of bacteriocines by Proteus species. Zentbl. Bakt. ParasitKde., I. Abt. Orig., 196, 385.

DE LouvoIs, J. 1969. Serotyping and the Dienes reaction on Proteus mirabilis from hospital infections. J. clin. Path., 22, 263. 
FinLAND, M. 1960. Treatment of pneumonia and other serious infections. New Engl. J. Med., 263, 207.

France, D. R. AND Markham, N. P. 1968. Epidemiological aspects of Proteus infections with particular reference to phage typing. J. clin. Path., 21, 97.

George, R. H. 1974. Comparison of different media for bacteriocine typing of Proteus mirabilis. J. clin. Path., 28, 25.

HuANG, C. T. 1966. Multitest media for rapid identification of proteus species with notes on biochemical reactions of strains from urine and pus. J. clin. Path., 19, 438.

Kashbur, I. M., George, R. H. AND Ayliffe, G. A. J. 1974. Resistotyping of Proteus mirabilis and a comparison with other methods of typing. J. clin. Path., 27, 572.

KIPPaX, P. W. 1957. A study of proteus infections in a male urological ward. J. clin. Path., $10,211$.

KRIKLER, M. S. 1953. The serology of Proteus vulgaris. Ph.D. Thesis, University of London.

Lewis, J. AND FeKetY, F. R. 1969. Proteus bacteremia. Johns Hopkins med. J., 124, 151.

Shortland-WebB, W. R. 1968. Proteus and coliform meningoencephalitis in neonates. J. clin. Path., 21, 422.

SkIRrow, M. B. 1969. The Dienes (mutual inhibition) test in the investigation of Proteus infections. J. med. Microbiol., $2,471$.

StORY, P. 1954. Proteus infections in hospitals. J. Path. Bact., 68, 55.

TRACY, O. AND THOMPSON, E. J. 1972. An evaluation of three methods of typing organisms of the genus Proteus. J. clin. Path., 25, 69. 